\title{
sciendo
}

WSB Journal of Business and Finance

Year 2019, Vol. 53, No. 2

eISSN 2657-4950

\section{Technological models of development and their applicability to a Baltic states}

\author{
Vladimir Chaplygin $^{\mathrm{a} 1}$ \\ awsB University in Gdansk, Grunwaldzka 238 a, Gdansk, Poland \\ (C) 2019 Vladimir Chaplygin. \\ This is an open access article distributed under the Creative Commons Attribution-NonCommercial-NoDerivs license (http://creativecommons.org/licenses/by-nc-nd/3.0/
}

DOI 10.2478/WSBJBF-2019-0019

\begin{abstract}
Purpose - To study the possibilities of a theory to establish a modern theory of economic growth, including the factors of institutions and changes in technologies. These factors are a set of rules with high coercive force to the agents' action, which form a particular mode/model of their adaptation, together with other institutions.

Findings - The research results may enrich an economic theory and practice in the area of business models applicability in Lithuania, Latvia and Estonia. The findings may assist an economic community to influence the general technological development within the national institutional systems.

Practical implications - The so-called institutional macroeconomics as a practical discipline (which has a very close connection with behavioural macroeconomics) may assist to explore the economic growth in a Baltic States from the point of view of changing institutions (firms, business community), labour markets and information.

Keywords: institutional theory, economic change, economic growth factors, models, technologies, institutions adaptation, business practice.Urban freight transport; Warehouse; location; linear regression; heat map; spatial analysis.
\end{abstract}

\section{$1 \quad$ Introduction}

There are two main branches of the research in institutional theory: the study of institutions and institutional changes and the study of technologies and technological changes. According to Veblen (Veblen, 1980, 2007), customs and stereotypes of thinking, which refer to the major part of the society, are considered to be institutions. According to North (North, 2010) institutions are game rules, including formal and informal limitations, and compulsion to fulfil the former and the latter. The detailed and evasive definition is given by Menard. In his opinion, institution is a complex of social and economic rules functioning in a certain historical period for which individuals or groups of individuals have no power in both short-term and medium-term periods. From the economic point of view, these rules are aimed to define the conditions under which individual or collective choice of resources allocation and use can be made. Differentiating institutions, markets and organisations, he insisted that institutions are not coordination mechanisms, but they 'aid to define socialhistorical conditions under which these mechanisms can form' (Menard, 1996).

In the framework of modern approaches in the theory of economic growth, the features of the influence on the economic dynamics of various factors are studied, with an emphasis on the factor of scientific and technological progress and

\footnotetext{
${ }^{1}$ Corresponding author. E-mail address: rusbanker@mail.ru
} 
technological changes. We focused on the institutional and technological factors of economic growth, using the accumulated knowledge within the framework of the modern growth theory (Alonso-Carrera \& Raurich, 2018; Gabardo, Pereima, \& Einloft, 2017; Samaniego \& Sun, 2016; Brancaccio, Garbellini, \& Giammetti, 2018; Iamsiraroj, 2016; Felice, 2016; Aguirre, 2017; Bartolini \& Santolini, 2017; Balachandran \& Williams, 2018), to show the individual problems and unresolved issues. An urgent task in relation to the current situation is to justify the policy of economic growth and in conjunction with the theoretical developments that economics has today. Particular emphasis was placed on the demonstration of various possible regimes and types of economic growth, based on the assumption of the technological function of the economic system, which predetermines possible strategies not only for scientific and technological development but also for economic growth.

\section{The Study of Economic Changes and Growth \& Research methodology}

Economic growth is carried out by a system of elements, and the set of these elements and their coherent dynamics influence the total growth rate of the economy. In this case, there is a change in the composition of the elements of the economy, the laws of their connection. This changes the economic structure and quality of economic growth. In this regard, the method of analysing the growth trajectory can be a structural analysis, as well as a morphological one. Considering that the rules of economic behaviour also change permanently, having a significant impact on the behaviour of agents, institutional conditions are highly relevant in the study of growth problems and the formation of economic growth policies. The natural resource factor by itself also determines the growth potential, as well as the accumulated scientific and technical reserves that set the mode of technology change and affect the technological efficiency of the economy.

Veblen considered that the principal factor providing economic development is the conflict amongst monetary sector, industry financing and the industry itself and between monetary and industrial culture. So initially representatives of institutional approach saw its practical application in the use of this theory in studying the problems of industrial organisations' development. The works of Nelson, Winter, Cantner, Hanush, Silverberg and Verspagen confirm this tendency (Nelson \& Winter, 2000; Cantner \& Hanusch, 2002; Nelson, 2008; Silverberg \& Verspagen, 1995; Williamson, 1975).

As far back as 1918, Hamilton asserted in his speech that institutionalism is practically the only theory that can unite economic science (presented by isolated doctrines at that time) because it shows how separate parts of economic system correlate with the whole. Neoclassical doctrines (mainstream school) that covered the theory of the general balance of Walras and A. Marshall's "partial equilibrium" in the local markets neglected the influence exerted by institutions on economy functioning (Blaug, 1994). The difference between the content of the mainstream research programme and the institutional economy was in the fact that exchange and procedures connected with it acted as endogenous variables in the 'mainstream' and production engineering, individual tastes were treated as exogenous variables specified for the given conditions for a long time. Thus tastes were assumed as stable - the 'independence' principle of the consumer was beyond any doubt. The principle of 'balance' and the abstract-deductive approach of knowledge of economic reality predominated. In institutional economy production, engineering and individual tastes and preferences are endogenous variables. They change in common in the course of changes in public relations, decision-making and operations in production and exchange. Only environment acts as an exogenous 'variable'(Hodgson 2003,2006).

Positioning institutionalism in the form of two schools - old and new ones (Williamson, 1975) - defined a 'certain dichotomy in the field of researches of institutions and technologies'. On the one hand, old institutionalists had a tradition to describe the role and importance of engineers, industrial organisation and industrial system (new industrial and postindustrial) in economic development, singling out the role of institutions and operating social structures. On the other hand, a new branch of institutionalism, headed by Coase, bricked up the research efforts concerning industrial organisation and branch structure of economy subject to the influence of the property rights and transactional costs on these changes (Coase 2000, 1993).

Certainly, initial resources and knowledge availability is a basic condition for the development. And whatever institutions could have been created, but without due competences, technological knowledge and resources, high social standard of living could have hardly been achieved. Moreover, shortage of the listed components would not allow creating necessary institutions because institutional planning and possibilities of institutions' perfection are also defined by the level of knowledge, technological development and resource provision.

From the moment of its origination, institutionalism assumed evolutionary approach. The following were the programme requirements of early institutionalism according to Homan (Homan, 1932):

1) underlining of change phenomenon (later on North (2010) and others institutionalists, J. Hodgson, in particular, paid attention to the factors of economic changes and to the necessity of working out of the theory of economic changes);

2) negation of regular (neoclassical - author's comment) theory because of its inaccuracy and isolation from management problems;

3) consideration of management mechanism as a basic appendix of economic theory; 
4) substantiation of descriptive (inductive - author's comment) method and quantitative researches.

At present, it is possible to allocate some directions where institutional theory can get useful results in the field of changes and economic growth study:

- innovations and technologies - working out of scientific and technical and industrial policy, based on the combination of analysis achievements on micro and macro levels in spite of the fact that institutional macroeconomics is developed much worse;

- designing of adequate (adaptive) behaviour models for managing subjects (formation of predicted reactions);

- management of transformation and development processes of separate markets and economic system as a whole;

- forecasting of the macroeconomic trajectory of economic system evolution (the theory of institutional changes and evolutionary economy).

However, to achieve these results, aggregated models of the firm and technological changes should be coordinated with the models of institutional modifications. Besides, it is necessary to use microeconomic results of new institutionalism at macro-level of the analysis of economic growth problems. An attempt to create harmonious descriptive institutional theory explaining macroeconomic changes through the changes on micro-level and, in particular, economic growth, was made by Mansur Olson in the book 'The Rise and Decline of the Nations' (1982). He linked the change in the number of distributive coalitions in the society with the effect of inhibition of introduction of new technologies that is accompanied by redistribution of resources and braking of economic growth, complicating regulation and increasing the costs of public administration (Olson, 2013).

\section{Technological Changes and Economic Growth}

The trajectory of scientific and technical development of many countries and the world system as a whole is connected, first, with augmentation of expenses on researches and workings out in the structure of gross domestic product that should be accompanied by the improvement in the quality of the research works and education. Second, it is connected with the export expansion of technologies in concrete technological niches that certain states have managed to occupy. And the third reason is the transformation of the niches when their borders become more and more indistinct and increases in the number of technological niches. For further effective development, it is important to establish the interaction forms of science, education and economy because these forms will define the dynamics of appearance and use of new knowledge to create specific products and services that will set certain rate of economic growth. As we see from the analysis, the value of research and development expenses itself does not guarantee a high rate of growth even in separate areas of development and does not promote its increase at all. The structure of the economy and institutions, including the organisation of technological chains in all directions of the activity, has more value for provision of the steady and high rate of growth. Probably, the value of expenses on research and development and rule creation - that it cannot be less than some value for the economy - are connected with the necessity to provide development of the future growth factors, diligently supporting competitiveness of technologies and technical machinery, but not with the necessity to maintain a certain rate of growth. In other words, such investment performs the function similar to the one that blood performs in a human body. The decrease in these expenses will create a shortage of technologies in the long term with the following problems of economic development and dependence on external investments.

To develop the strategies of scientific and technical development of separate countries, it is necessary to approximately define the possibility to realise any strategy, at least on the basic parameters.

To achieve this, it is necessary to algorithmise the analysis and to estimate the initial (current, at the moment of consideration) state of economic system objectively, having accepted, for example, the level of three basic indicators for such estimation: 1) resources, including natural, physical and human capital; 2) institutional potential, including basic institutions, social structure, trajectory of social evolution, mode and way of life, traditions and religious orientation and influence (actually, this second point defines the trajectory of social development, its stylistics and quality of the institutions that are responsible for social system functioning); 3) scientific-technical and technological potential including fundamental and applied sciences, techniques, technological policy and current educational level and technical equipment of all processes.

Let the vector of raw materials be $\mathrm{R}=\{\mathrm{R} 1, \mathrm{R} 2, \ldots \mathrm{R}\}$ used at the stages of technological processing $\mathrm{C}=\{\mathrm{C} 1, \mathrm{C} 2, \ldots$ $\left.\mathrm{C}_{\mathrm{n}}\right\}$, presenting the core of the given technology received for the account of combinatory connection of two technologies used for a long time (out-of-date technologies) turn to the vector of production $\mathrm{P}=\{\mathrm{P} 1, \mathrm{P} 2, \ldots \mathrm{P}\}$ consumed by a certain totality of consumers $\mathrm{U}=\left\{\mathrm{U} 1, \mathrm{U} 2, \ldots \mathrm{U}_{z}\right\}$. If a new technology is created, vector 'product' should be treated as 'technological decisions', or combinatorially appearing technologies. Three types of multipliers, $\mathrm{M}_{\mathrm{RC}}, \mathrm{M}_{\mathrm{CP}}$ and $\mathrm{M}_{\mathrm{PU}}$, are designated accordingly in Figure 1. Photoelectronics, microelectronics (semiconductors production) and the layering processes of wide application acts as consumer directions for the considered technology. Thus, the layering technology in electrostatic field extends to the production area of industrial goods used in other technological chains and for production of consumer goods. 


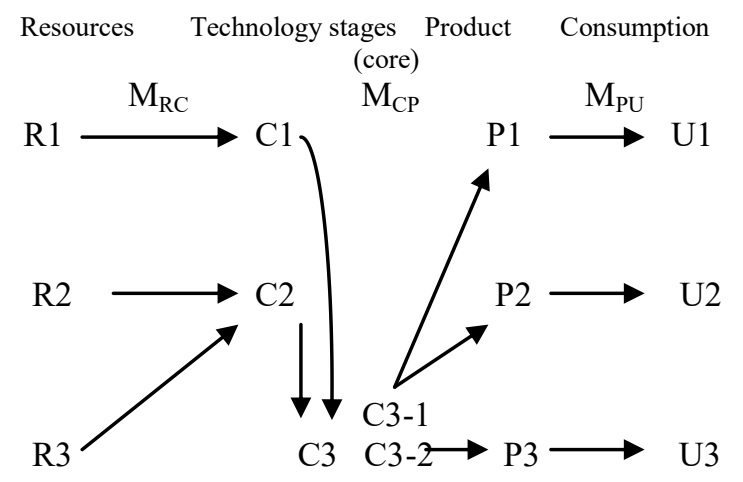

Figure 1. Combinatory Use of Resources; Receiving of Technologies P1, P2 and P3; and Consumer Products U1, U2 and U3. The General Scheme of Technological Changes Reflecting One of the Cases.

Technology growth is not only the change in its core and periphery for the account of expansion of functions and additional operations, but it is also the improvement in technology efficiency indicators (material capacity and energy intensity) and profitability of applied technology (profitability of investments into technology and product produced with it). Technological growth is accompanied by the increase in the number of highly efficient technologies and obligatory combinatorial effect. If there are three types of the resource (separate systems, materials and construction elements can be used) for technologies creation and development, they are received differently at the stage of use C1, C2 and C3 (see Figure 1). Two resources can be received at stage $\mathrm{C} 2$ and one resource at stage $\mathrm{C} 1$. At stage $\mathrm{C} 3$, no resource can be received directly. The variant is possible when there are three types of resource at stage $\mathrm{C} 1$ or $\mathrm{C} 2$ at a time or no one as all three resources will be at stage $\mathrm{C} 3$. Certainly, there is a possibility that each stage will receive its own resource, that is, there will be correspondence between the figure designating the type of the resource and the figure designating the stage of technology (processing) development. It is important to notice that after any two stages have been passed, for example, $\mathrm{C} 1$ and $\mathrm{C} 2$, the result of the performance of these stages is received at stage $\mathrm{C} 3$. Thus, stage $\mathrm{C} 3$ can include two independent stages of technology perfection or resource processing - C3 to $\mathrm{C} 1$ and $\mathrm{C} 3$ to $\mathrm{C} 2$. Stage $\mathrm{C} 3$ to $\mathrm{C} 1$ provides technological outcomes (or products) $\mathrm{P} 1$ and $\mathrm{P} 2$, stage $\mathrm{C} 3$ to $\mathrm{C} 2$ provides outcome $\mathrm{P} 3$. There can also be a combination here depending on the possibilities of stages $\mathrm{C} 1$ and $\mathrm{C} 2$. There can be direct arrows to P1 and P2, passing P3, or to one of technological (product) lines $\mathrm{P}$ from them. Technological possibilities $\mathrm{P} 1, \mathrm{P} 2$ and $\mathrm{P} 3$ give corresponding sets of blessings on the directions U1, U2 and U3. For each kind of combinatorial augmentation, there can be a combination depending on the technologies content, conditions of their interfacing and functions of new technology. Technological possibilities in this part will depend on multiplication parameters for separate phases of the chain of technology development $-\mathrm{M}_{\mathrm{RC}}, \mathrm{M}_{\mathrm{CP}}$ and $\mathrm{M}_{\mathrm{PU}}$, each of them is measured by the number of possible combinations on the given phase. For any technology, the scheme similar to the one shown in Figure 1 can be constructed. It is built by analogy with 'input (resources) - technology core - output (consumer possibilities)'. There are various combinations inside. Figure 1 only reflects one of the particular cases. In general case, greater number of initial resources can be used, which give a certain vector of technologies or products $\mathrm{P}$, which then create consumer costs $\mathrm{U}$, singling out separate product (consumer) directions.

From the macroeconomic point of view, various technologies co-operate on each element R, C, P and U and the force of this interaction being unequal on each element. It is because of the absenceof principlefor some kinds of technologies, as these technologies are not interfaced.

Two important parameters can be introduced, which, at different levels, characterise the relations of the process of technological change of these levels 'diversity' set by $\mathrm{M}_{\mathrm{RC}}, \mathrm{M}_{\mathrm{CP}}$ and $\mathrm{M}_{\mathrm{PU}}$ accordingly. Each level is characterised by a set of rules: search and transformation of the resource (R), the stage of processing $(C)$ and technology or product realisation (P) and creation of product direction (U). The technology prospect at macroeconomic level of its development can be estimated by current dynamics of these factors $\mathrm{k} 1=\mathrm{M}_{\mathrm{CP}} / \mathrm{M}_{\mathrm{RC}} ; \mathrm{k} 2=\mathrm{M}_{\mathrm{PU}} / \mathrm{M}_{\mathrm{CP}}$. Thus there appear the following modes of technological changes that are entirely caused by the general condition of economic infrastructure, equipment, technologies and scientific and technical reserve created in the country, state of technological chains and cooperation and the state of domestic market and many institutions (Figure 2).

Mode 1. It is the mode of proportional technological development when $\mathrm{k} 1=1$ and $\mathrm{k} 2=1$, that is, variety at different stages of technological changes is equal. In practice, this mode is extremely rare, but it is necessary to specify that, 
theoretically, it is possible.

Mode 2. It is the mode of increasing technological development (technology) when $\mathrm{k} 1>1$ and $\mathrm{k} 2>1$, that is, the process changes from smaller combinations to larger number of technological combinations that still gives larger number of consumer directions and programmes further technological changes according to combinatorial principle in the long term.

Mode 3. It is the mode of narrowed technological development when $\mathrm{k} 1<1$ and $\mathrm{k} 2<1$, that is, combinations of resources surpass the combinations of processing stages and appearing technologies also surpass the combination of possible consumer directions in diversity. Such technology can exist. It can even demonstrate some efficiency or be inefficient. If there is no substitute, and it serves a very narrow consumer segment, and this segment is strongly dependent on this technology, it will exist. Of course, generally, the mode of narrowed technological development is mostly subject to cutting down when the alternative technological variants appear. There are two more possible modes of technological changes that cannot be neglected.

Mode 4. The mode of 'locking' technological development when $\mathrm{k} 1>1$ and $\mathrm{k} 2<1$ or combinations of technologies surpass the combinations of resources and the diversity of consumer directions. In this case, these technological possibilities should be additionally studied to know how they are connected with other technologies in order to have increasing development mode, having changed factor $\mathrm{k} 2$.

Mode 5. The mode of 'comprehensive' technological development at which $\mathrm{k} 1<1$ and $\mathrm{k} 2>1$ and the diversity of technological possibilities is sharply inferior to resource diversity and consumer directions that arise based on the use of this technology. In this case, technology obtains 'monopoly', especially if consumer directions are generated and strongly depend on this technology. The example is energy technologies. There is the so-called natural monopoly of the given technology.

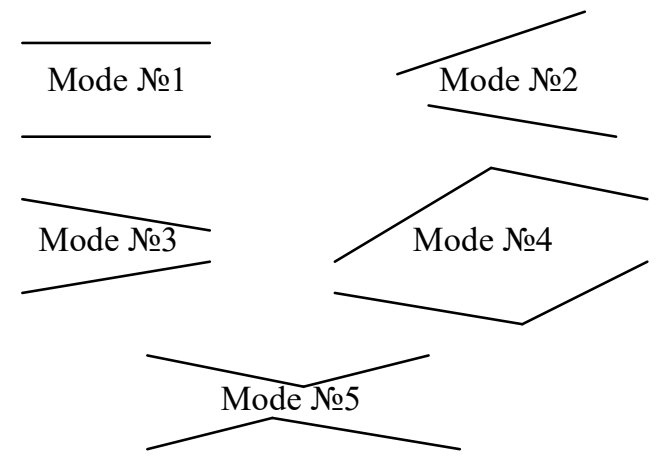

Figure 2. Modes of Technological Changes

Each of the modes arises on certain kinds of technologies and on their certain set, but the technologies are connected. Thus, in macroeconomics, there is a set of modes of technological development, and investments into technologies should consider both the meaning of the mode of technological development and value of the specified factors on separate technologies. Besides, the possibility or necessity of change in technological development mode should be taken into consideration. Value $\mathrm{k} 3=\mathrm{M}_{\mathrm{PU}} / \mathrm{M}_{\mathrm{RC}}=\mathrm{k} 1 \mathrm{k} 2$ will be a useful auxiliary parameter.

Then we will make up a matrix where lines will mean three major parameters just specified, setting a vector of economic system development and eventually causing the rate of growth (speed of development) for the account of a certain combination of these three parameters that is often unique for each country. Having designated pronounced presence of each parameter separately for the given subject (leadership) as 'maturity' or 'high level' with sign '+' (It is possible to designate it as 1 (unit), and the absence and weak development was designated as zero), and the absence of any of them as '-', we will have a matrix of the state of the subject at the initial stage. It is simplified enough but is useful for the analysis of trajectories of the development, including scientific and technical development. From Table 1, there are eight possible states - strategies of system development (columns) depending on the combination of basic parameters (presence-absence).

Table 1. Trajectories of Economic System Development (Lines are basic parameter, columns are trajectory potential of scientific and technical development and growth trajectory)

\begin{tabular}{|l|l|l|l|l|l|l|l|l|}
\hline & 1 & 2 & 3 & 4 & 5 & 6 & 7 & 8 \\
\hline 1$)$ & + & + & + & + & - & - & - & - \\
\hline 2$)$ & + & + & - & - & - & - & + & + \\
\hline 3$)$ & + & - & - & + & - & + & + & - \\
\hline
\end{tabular}


Thus, there are eight models (each model has its own strategy of growth, quality and the trajectory of scientific and technical development. Such simplified classification, nevertheless, is useful at the development of priorities of scientific and technical development and formation of corresponding strategy of the state) of economy development (according to the combination of levels of development/underdevelopment of basic parameters): model 1 is the ideal trajectory of growth and scientific and technical development when all three parameters have high level and strengthen each other; model 2 is the countries of the Middle East exporting oil, which buy scientific and technical production for the resources, not possessing their own scientific and technical achievements (for these countries, institutional potential is not low; they have their own social system based on traditions and religion); model 3 is developing countries where nothing is developed except resources and institutional development potential is low; model 4 is self-sufficient countries according to resources and technological level, but with transitive and unstable regimes, or not efficient institutional system (transitive countries, e.g. Russia, separate CIS countries and countries of Eastern Europe); models 5 is the worst standard as opposed to model 1, (conditionally, it is possible to take any strongly backward or very poor country for this model, in particular, a country of sub-Sahara Africa with hunger problem); model 6 is a theoretical structure that is probable, but, at present, there is no vivid example of this model, probably, it is Ukraine, where at rather modest resources unstable institutional structure is all the same combined with the accumulated scientific and technical reserve of the Soviet period; model 7 is Japan, Finland and Sweden, which possess modest resources, especially Japan, but high institutional potential of development and scientific and technical potential (recently, the experts has called Finland as almost the sample of 'economy of knowledge'. Anyway, in a rating of the countries, it occupied the leading positions in the second half of 2000s); model 8 is Switzerland and small states, for example, Cyprus and island states specialising on tourism and services, including financial services, with agriculture and very insignificant industry, or without it. They have extremely limited resources. Scientific and technical achievements are absent or are extremely modest, but the institutions' system is stable and supports their specialisation in services and tourism industry.

To choose priority directions of scientific and technical development, it is necessary to use the method of 'achieved', but such method assumes realisation of the following principles:

- first, the principle of 'material provision', estimation of energy, materials and fixed capital (machines, equipment, etc.) and financial resources (investments), the latter being especially important;

- second, the principle of 'non-material provision', characterising the order of interaction of the system elements, methods of the management system and its elements management, including software and control systems of the processes.

Being guided by these principles, it is easy to consider the basic indicators in the following way: the first indicator, resources, by estimating the reserves of mineral resources, power (generating) capacities, funds, gold exchange reserves, the budget and so on; the second basic indicator by estimating social system, political, security, defence and law enforcement, fiscal (monetary) and other institutions; the third indicator by estimating the state and level of education, achievements of science and technology and available accumulated reserves: patents, useful models, inventor's certificates and so on.

To generate the strategy of economic growth and to define the trajectory of scientific and technical development of the country, it is necessary to take some steps.

1. To estimate the current model of economic system functioning (according to the presented matrix).

2. To define the dynamics of change of the basic parameters. Theoretically, on long intervals, the country can move according to the specified models, because of the movement on this or that trajectory (e.g. because of the implementation of certain reforms).

3. To designate possible priorities of the development of the given system. To solve the problems of the third step, it is necessary to outline the set of 'indisputable' priorities for the concrete system.

4. Estimation of tendencies and risks and working out of scenarios (variants, trajectories) of scientific and technical development.

As a rule, the vectors of scientific and technical development are defined to achieve most often pursued purposes (priorities). They can be the following:

- to achieve power and food independence;

- to provide military priority (defence security, territorial integrity);

- to increase the consumption level and life expectancy of the people,

- to provide ecological, information safety and so on.

Such purposes cause the necessity of constant perfection of all elements of the system and increase in subject's competitiveness at the world level. But in order to choose the priorities of scientific and technical development, it is necessary to develop the main principles and be guided by them. Some of them are presented below.

A. Definition of perspective sectors and kinds of activity (basic branches) and directions of activity to achieve each of the purposes that are set for the system (definition of the technological core). 
B. Choice of key technologies, know-how and technological decisions, putting these sectors and kinds of activity and direction to the leading world positions according to point A (determination of some technologies and their cores that will make the nearest and remote prospect).

C. Making up of a list of the accompanying technologies that are not the key ones (in contrast to point B) but obligatory at the given stage of development to achieve the purposes (definition of the periphery and the ways of its perfection).

G. Comparability of the expected result of the purpose achievement and the expenses for its achievement, registration of alternatives and inertia of the competing systems development.

D. Constant monitoring of external conditions to acknowledge the urgency of the purposes for timely updating of priorities and maintenance of application area of efforts and functional variety at the due level necessary for steady economic growth.

Realisation of the specified principles with the help of which it is possible to build the trajectory of scientific and technical development assumes estimation of the reasons of change of the demand for these or those technologies, analysis of technological economy structure developed by the current moment (diagnostics). It is possible to single out three main 'reasons' of the demand for technologies: 1) human vital activity and the basic needs (biological, physical, cultural, etc.); 2) protection of the nature and the society against external threats, such as cataclysms, ecology, climate change, wars, conflicts, and space; 3 ) cognition of the surrounding world (micro and macro world).

Deep down, these three directions of the demand for technologies cause both appearance and development and perfection of technologies. In this connection, the process of appearance of technologies, which is still poorly described by economic science, is presented in three ways that can be manifested separately or can be somehow combined.

First, 'heuristic' way of technologies appearance when absolutely new technologies appear owing to certain discovery, invention, the creation of new material, mechanism and device. The frequency of such events is reduced, that is, 'epochmaking' events seldom occur.

Second, 'incremental' way of development of technologies when, after 'epoch-making' events, there is improvement in the perfection of the known technologies and traditional ways of production that provides efficiency increase.

Third, 'combinatory' way of development of technologies when new technologies appear or traditional ones are improved owing to parallel and consecutive combination of separate technologies. Thus big investments are not necessary and new epoch-making discovery should not be expected. 'Combinatory' principle does not reject the principle of 'creative destruction' on which the majority of modern models of technological development are based, but, on the contrary, it underlines the development specificity of modern techniques and new technologies when the resource cannot be borrowed from previous combinations and there is a necessity to create it for a new combination in the economy. Thereby the effect of multiplication on new combinations in the economy has quite a different basis connected with the process of creation and development of techniques and technologies. From this point of view, the multiplication effect of new combinations depends on the state of scientific and technical personnel and conditions of research work, but not only and not so much on the finance. Considering these facts, the importance of the current economic structure and its efficiency sharply increases. But it is also impossible to increase the efficiency of such initial structure without due financing. If having financed a new combination, money is put into circulation and the combination is created for a certain period of time, inefficient structure can transform money increment into amplifying inflationary pressure, which will increase the costs of this new combination and will create the necessity of additional financing that will be impossible to provide because of unforeseen changes, increase in prices and percent.

A variety of technologies and a large number of combinations on the interfaced technologies and even technologies, which seem to be not connected in any way with each other (from different kinds of activity), nevertheless, can provide important combinatory combinations that will result not only in the increase in the efficiency of the given technologies class but also will expand other technological possibilities, replacing 'heuristic' class of technologies.

being the research approach used in this study.

\section{Economic Growth and Technological Development of the Baltic States}

In order to identify the changing problems of the development of the Baltic States in the light of European integration, it is necessary to conduct a diagnosis of the macroeconomic model of their dynamics as accurate as possible, to identify the features of technological development, because it is the difference in technologies that ensures differences in economic development.

It is important to note that in order to maintain regular production growth, investments should not only be large but should also constantly increase, providing technological updating. If we recall the model of economic growth developed by Roy Harrod, then, according to this model, if in a certain period of time the investments exceed the volume necessary to maintain growth, then the production capacities created in the future, all other things being equal, will be redundant.

Definitely, the schemes for subsidising individual factors of production may be criticised, because they quietly change 
the relative prices of a factor without simultaneously changing the prices in the markets, that is, imbalance of the 'costprice' mechanism, and what is also important in investment is savings (prices and production levels must be compatible: if rise of prices is too high, and the amount of cash remains unchanged, then the interest rate follows this price movement, whilst interest in investments is weaker, and as a result, production can only decrease, since otherwise established consumption habits will lead to excess savings).

In order to verify the development dynamics, the IMF, as a rule, use an empirical model MULTIMOD, which includes macroeconomic data for the groups of seven industrialised countries (the United States, Japan, Canada, Germany, France, Italy and the United Kingdom), countries of the Organization for Economic Cooperation and Development (OPEC), Asia and Latin America states. Each of these national or regional models is connected with the others through bilateral trade flows and through capital flows and exchange rates, which in turn affect domestic financial markets. Nevertheless, such approaches cannot be applied in a 'pure' form for a group of states that are heterogeneous in their economic development, precisely because the factors of the macroeconomic environment included in the analysis (output and growth, inflation and budget deficit; current account; costs EU partner countries; labour productivity; wages and taxes; changes in monetary and financial goals; subsidising production factors: capital and subsidies for employment; subsidising production: subsidies income and against wage investment) are unique.

In order to intensify and fully utilise the mechanisms of economic development of the Baltic states under consideration, it is necessary to determine the trajectories of their economic dynamics and to assess the possibilities (potential) of further economic development, given, inter alia, the manufacturability of their economic systems. Therefore, the method used for determination in further research is the structural analysis of the dynamics of the GDP of countries - Lithuania, Latvia and Estonia, which allows to establish the existing model of the economic dynamics of each country and its impact on further development, as well as a structural analysis of the level of technology development and the impact of investments on the change in the structure of 'new-old' technology.

On the basis of the theoretical considerations made above, we consider the conditions for the development of the Baltic countries, identifying a model of economic growth and an established strategy for technological development. Different elements of GDP make their own contribution to the overall rate of economic growth, and the value of each element varies from year to year. There are reasons for this, and it is that they should become an important area of macroeconomic research, especially when setting the goal of ensuring sustainable economic growth (crisis-free development). For a quantitative assessment of the contribution of each component of GDP to the overall growth rate, we will resort to the so-called 'structural formula'.

$\mathrm{g}=\mathrm{g}_{\mathrm{c}} \mathrm{c}+\mathrm{g}_{\mathrm{I}} \mathrm{n}+\mathrm{g}_{\mathrm{G}} \mathrm{a}+\mathrm{g}_{\mathrm{NX}}$

where $\mathrm{g}=(1 / \mathrm{Y}) \mathrm{dY} / \mathrm{dt} ; \mathrm{gc}=(1 / \mathrm{C}) \mathrm{dC} / \mathrm{dt} ; \mathrm{gI}=(1 / \mathrm{I}) \mathrm{dI} / \mathrm{dt} ; \mathrm{gG}=(1 / \mathrm{G}) \mathrm{dG} / \mathrm{dt} ; \mathrm{gNX}=(1 / \mathrm{NX}) \mathrm{d} \mathrm{NX} / \mathrm{dt}, \mathrm{c}=\mathrm{C}$ $/ \mathrm{Y}, \mathrm{n}=\mathrm{I} / \mathrm{Y}, \mathrm{a}=\mathrm{G} / \mathrm{Y}, \mathrm{b}=\mathrm{NX} / \mathrm{Y}$ is the structural parameters of the gross domestic product in terms of costs $\mathrm{Y}=\mathrm{C}+\mathrm{I}$ $+\mathrm{G}+\mathrm{NX}, \mathrm{C}$ is the gross consumption, I is the gross investment, $\mathrm{G}$ is the government spending and NX is the net export.

We apply this formula to assess the accuracy of calculations for Lithuania, Latvia and Estonia, highlighting the specific features of economic dynamics and the contribution of GDP components to growth for each country. The time interval accepted for the study covers the period from 2000 to 2017.

Lithuania, Latvia and Estonia demonstrate a similar and different style of economic development. Lithuania, Latvia and Estonia, as well as Germany in 2009, show a rather significant decline in GDP. However, all other years the growth rate is positive and, on an average, exceeds the growth rate of the German economy. For Lithuania, Latvia and Estonia, the growth rate in the period 2011-2017 was lower, on an average, than in the period 2000-2008. Thus, there are fundamentally excellent characteristics of economic dynamics for the countries under consideration. The reasons lie not only in the institutional and structural difference in building the economies of these countries but also in the structural dynamics of the gross domestic product being created. There are four main parameters that can be used to evaluate the model of economic dynamics:

- the GDP component, which makes the main contribution to the economic growth rate;

- the GDP component that has the greatest impact on economic growth;

- a component of GDP that provides resistance to a negative pace in the 2009 crisis;

- the prevailing model of economic dynamics - according to the dominance of gross consumption, investment expenditures or the mixed influence of both components (without identifying the uniquely dominant component).

The result of the characteristics of the structural dynamics of the Baltic countries is shown in Table 3. 
Table 3. The predominant generator (the leading component of GDP in terms of contribution to growth) and the model of economic dynamics

\begin{tabular}{|l|l|l|l|l|}
\hline Country & Main growth generator & Component of growth restraint & $\begin{array}{l}\text { Component of anti- } \\
\text { crisis dynamics (2009) }\end{array}$ & $\begin{array}{l}\text { Model of economic dynamics: } \\
\text { consumer; investment; mixed } \\
\text { (without pronounced dominant) }\end{array}$ \\
\hline Lithuania & Gross Consumption & Net Export; Investment expenses & Net export & Consumer \\
\hline Latvia & $\begin{array}{l}\text { Gross consumption; } \\
\text { Investment costs }\end{array}$ & Net exports; Investment costs & Net exports & Mixed \\
\hline Estonia & $\begin{array}{l}\text { Investment expenses; Gross } \\
\text { consumption }\end{array}$ & Net exports; Investment costs & Net exports & Mixed \\
\hline
\end{tabular}

The Baltic States - Lithuania, Latvia and Estonia - show fairly similar dynamics. According to the World Bank, they show a rather high growth rate; however, in 2009, they have an absolute decline in GDP, moreover, a significant one. At the same time, there is a difference in the structural quality of this dynamics. Thus, the Lithuanian economy shows a consumer growth model, whereas the economies of Latvia and Estonia are a mixed model of the structural dynamics of GDP. In these two countries, gross consumption and investment spending contribute the most to economic growth. In some years, net exports. The number of points where the contribution of gross consumption is higher than the investment, expenditures exceeds the number at which investment expenditures dominate over the contribution (over gross consumption). However, the contribution of these components is comparable. Net exports and investment costs also have a chilling effect (negative contribution). However, in the crisis year of 2009, it is precisely the net export component that provides a positive contribution to the pace for the economies of Lithuania, Latvia and Estonia. Gross consumption in Lithuania has a more prominent contribution to the growth rate (dominant influence) than that in Latvia and Estonia. Therefore, the dynamics model of Lithuania - the consumer, Latvia and Estonia - is mixed. Moreover, these three states responded identically in the macroeconomic sense to the crisis of 2009 - through the component of net exports, other components of GDP made a negative contribution to the growth rate.

A macrostructural analysis of the dynamics of GDP confirms that investment expenditures quite strongly affect economic dynamics. At the same time, investments are distributed in each economic system in its own way, between financial and non-financial assets, as well as between old and new technologies. As modern economic growth is based on a rapidly updated technological basis of the economy, the structure of the distribution of investments is the inherent characteristic of the prospects for economic development of each country striving to use the achievements of technological progress.

For the countries considered in this study, at the above time interval, we analyse the structure of investments in new and old technologies, which allow us to assess how the process of technological updating is going. The distribution of investments according to various technological capabilities ensures the general adaptability of the economic system, which determines the prospects for its development as a whole and structural dynamics in particular.

Technological ability is understood as the ability of the economic system to achieve the results with the least expenditure of resources, because of the improvement in the technical and technological base of the economy. In this study, the level of manufacturability is determined by the ratio of the volume of production on new technologies (the volume of high-tech products) to the volume of production on old technologies (total production minus the volume of production on new technologies). Investments in new technologies mean R\&D expenditures, and investments in old technologies mean the difference between the total amount of non-financial investments and R\&D expenditures. The analysed time period is the range of 2009-2016.

The costs of new and old technologies in the countries in question have a different effect on the level of overall technological effectiveness of the economy.

Let us show this influence by conducting an empirical-econometric analysis according to the data of the World Bank. It is necessary to establish, at the expense of which investments the technological effectiveness of the economy changes in new or old technologies, because this influence reflects the importance of incentives for innovation and characterises innovative development.

The prevailing technological development models are described in Table 4.

Table 4. The model of technological development of the Baltic countries, 2009-2016 (the impact of the investment structure on the level of manufacturability

\begin{tabular}{|l|l|l|l|}
\hline Country & Investing in new technologies & Investing in old technologies & Technological development model \\
\hline Lithuania & $\begin{array}{l}\text { On an average, reduce technological } \\
\text { effectiveness }\end{array}$ & Increase technological effectiveness & Delivery of technological positions \\
\hline Latvia & Decrease manufacturability & Decrease manufacturability & Technological degradation \\
\hline Estonia & Increase manufacturability & Increase manufacturability & Technological breakthrough \\
\hline
\end{tabular}


For Lithuania, the costs of new technologies acted towards lowering the technological level, whereas for old technologies, the level of manufacturability was increasing. The cost of old technologies was, on an average, 10 times higher than that of new technologies. This mode of development can be described as 'surrender of technological positions'. It should be noted that the highest technological level in Estonia is up to 0.3 ; in Lithuania, it varies from 0.12 to 0.18 . In Latvia, the lowest technological level was in the range of 0.01 to 0.03 . Therefore, it is no coincidence that Latvia shows a model of technological degradation.

As follows from the calculations, the costs of new and old technologies are in the direction of reducing manufacturability. This mode blocks the innovative development of a given country. Therefore, in spite of the not bad economic growth rate, nevertheless, the problem of technological development is an urgent task for Latvia.

Estonia shows a technological breakthrough model. Investments in new and old technologies are working towards increasing the overall manufacturability of the economy.

Although investments in old technologies are about 10 times larger than those in new technologies, nevertheless, the investment process is aimed at increasing the overall level of technological effectiveness of the economy. Moreover, this level in value reaches 0.3 .

As follows from the analysis, there was a significant difference in the technological level of countries as well as the mode of technological dynamics, defined by the ratio of investments in the technological structure (new-old technologies). Therefore, in addition to the task of maintaining a relatively high growth rate, it is necessary to solve the problem of technological updating, influencing the parameters of investment distribution and institutional regimes that stimulate innovative development.

\section{Research Approach}

Thus, it is difficult enough or almost impossible, if to be exact, to divide institutional factors of economic growth. However, the influence of institutional factors on the rate of economic growth can be estimated as follows.

First, the rate of economic growth has been determined by the rate of population increase. If the population growth is slowed down, as it follows according to some forecasts, it will also decelerate economic growth. These conclusions can have no confirmation in the modern economy, where the rate is ensured by information, knowledge and technological rush.

Second, the rate of growth depends on the level of the 'living standard' by the given moment, the speed of change in incomes of the least secured group of the population and the speed of change in intellectual capital. The greater these values are, the higher the overall growth rate of income. However, the more the volume of information, the more the change in information processed by the agent in the time unit, the lower the growth rate will be.

Third, institutional conditions of economic growth, which can be reduced to agents' reactions to changes and to influence of average speed of changes (it is clear, that the change of each institution is unique as the content of one institution differs from the content of the other institution), can affect growth in the following way: the higher the sensitivity and the speed are, the lower the rate of growth will be with very high probability. At high sensitivity, the agents simply reject the changes of institutions, increase in transactional costs, and their benefits grow more slowly.

It is shown how a scientifically based strategy of economic growth should be built (an algorithm to formulate decisions within the framework of economic growth policies is proposed), taking into account the emerging types of growth regimes, when the economic system detects different dynamics, going from one state determined by one set of factors and conditions to another, already with a different set of factors and conditions. In addition, a set of factors may persist for some impressive period of time, but here the weights, that is, their significance, change. The role of technology and institutions in influencing economic growth has been investigated, as well as models of economic policy, a system growth model, have been proposed, which allow decomposing the impact of a number of factors, defining types of policies for changing growth strategies. A useful algorithm has been defined to substantiate a science and technology policy that meets the level of existing and developed growth factors in order to enhance the economic dynamics by improving the technological effectiveness of the system, ensuring proportionality of the influence of technologies and institutions on the growth rate.

It is proved that the increase in the technological level of the economy is possible because of the increase of results in the field of used (old) and the use of new technologies. However, over the considered time interval, the number of advanced production technologies decreased by a quarter. In the processing industries, there is a general loss of advanced technologies with an increase in the number of developed advanced technologies. If this continues, there will be a 2 -fold decrease in the number of technologies for the next 8 years. Consequently, the key goal is to increase the overall adaptability of the economic system with a common vector for the appropriate distribution of investment between the old and new technological capabilities. This fundamentally clarifies the algorithm for the formation of national development priorities. In essence, a theoretical justification is given with the necessary empirical verification that the old technologies, which are also substantially underdeveloped, require assignment to the priority areas of development. Directing resources only to the field of new technologies can dramatically increase the imbalances in the development of the economic system, although this does not mean abandoning such prioritisation. Hence, institutional reforms can often decelerate economic growth 
regardless of the incentive motives of the carrying out. The technological level of the economy will also be an indicative factor here defining economic dynamics together with the changing institutions.

Similar to every study in economic sciences, this study has the following limitations.

1. The model developed in the study is based on the survey of literature carried out for the present study. The research model is limited to the study of economic growth and technological changes; it is recognized that a number of other constructs have been included in the study to make it more appropriate to the fast technological development.

2. A further limitation is that the study findings may not be applicable across different economic and political settings; researchers may find that results differ from one state to another one.

\section{Directions for future research}

The outcomes of this research may enrich an economic theory and practice in the area of business model applicability. The findings may assist a business community to influence the general technological development within the national institutional systems.

1. Specific research directions include identifying whether economic growth models and/or technological changes can be used in order to identify the possible directions of economic development.

2. Further investigation of the relation between the development of economic growth and a type of technological development can be undertaken.

Summing up the general result, we note that our study allows us to formulate some important conclusions arising from the structural dynamics of the countries examined, which are usually not taken into account when implementing macroeconomic policies and in comparative intercountry analysis. In the classical version, these measures are aimed at changing aggregated values - gross product, investment, employment and so on. At the same time, it is the structural quality of the economy that determines the possibilities for its further dynamics.

The Baltic countries demonstrate a mixed model of economic growth, that is, the main contribution to the growth rate is distributed between gross consumption and investment spending, for example, Lithuania, Latvia and Estonia in 2009 (similar to Russia). This was the only year of absolute reduction in GDP in the considered time interval.

Second, on an average, the growth rate of economies after the crisis of 2009 was lower than that before this crisis.

Third, for all countries reviewed, investments in old technologies are significantly superior to investments in new technologies. However, the higher the initial technological level of the country, the lower this superiority. For the most developed countries in terms of 'technological level', the technological level is growing with investments in new technologies. Thus, there is a fundamental difference in the susceptibility of technological updates to different countries.

Thus, various regimes of macroeconomic dynamics of a number of Baltic states were determined, including their different sensitivity to the costs of new and old technologies that determine the possibilities of innovative development. The usefulness of the analysis lies in the fact that it allows you to take into account aspects of structural dynamics in terms of further substantiation of macroeconomic policies and stimulation of innovation, which must necessarily differ in these countries. Consequently, the transfer (copying) of development institutions and macroeconomic policy instruments (methods) cannot be considered as a reasonable method, because it cannot lead to the expected and desired results for this group of countries because of the significant differences in the structural dynamics and the reaction of their economic systems to financing innovation and the introduction of new technologies.

\section{References}

Aghion, P., \& Howitt, A. (1992). Model of Growth through Creative Destruction. Econometrica, 60(2), 323-351. https://doi.org/10.2307/2951599

Aguirre, A. (2017). Contracting institutions and economic growth. Review of Economic Dynamics, 24, 192-217. https://doi.org/10.1016/j.red.2017.01.009

Alonso-Carrera, J., \& Raurich, X. (2018). Labor mobility, structural change and economic growth. Journal of Macroeconomics, 56, 292-310. https://doi.org/10.1016/j.jmacro.2018.03.002

Balachandran, B., \&Williams, B. (2018). Effective governance, financial markets, financial institutions \& crises. PacificBasin Finance Journal, 50, 1-15. https://doi.org/10.1016/j.pacfin.2018.07.006

Bartolini, D., \& Santolini, R. (2017). Political institutions behind good governance. Economic Systems, 41(1), 68-85. https://doi.org/10.1016/j.ecosys.2016.05.004

Baumol, W. (2004). Red-Queen games: arm races, rule of law and market economies. Journal of Evolutionary Economics, 14(2), 237-247. https://doi.org/10.1007/s00191-004-0207-y

Blaug, M. (1994). Economic Thought in retrospective review. Moscow: Business.

Brancaccio, E., Garbellini, N., \& Giammetti, R. (2018). Structural labour market reforms, GDP growth and the functional distribution of income. Structural Change and Economic Dynamics, 44, 34-45. 
https://doi.org/10.1016/j.strueco.2017.09.001

Cantner, U., \&Hanusch, H. (2002). Evolutionary economics, its basic concepts and methods. A tribute to Mark Perlman, Editor of the Journal of Evolutionary Economics 1991-96.In H. Lim, U.K. Park, \& G.C. Harcourt (Eds.), Editing Economics. Essays in honor of Mark Perlman (pp. 182-207).London: Routledge. https://doi.org/10.4324/9780203472200

Coase, R. (1993). The firm. The market. The law. Moscow: Business.

Coase, R. (2000). Interview at the Founding Conference of International Society of New Institutional Economy. St. Louis, 1997 September $17^{\text {th }}$. Quarterly Bulletin of Economists Club, 4, 1-28.

Felice, G. (2016). Size and composition of public investment, sectoral composition and growth. European Journal of Political Economy, 44, 136-158. https://doi.org/10.1016/j.ejpoleco.2016.07.001

Gabardo, F. A., Pereima, J. B., \& Einloft, P. (2017).The incorporation of structural change into growth theory: A historical appraisal. Economia, 18(3), 392-410. https://doi.org/10.1016/j.econ.2017.05.003

Hartwell, C. A. (2016). The institutional basis of efficiency in resource-rich countries. Economic Systems, 40(4), 519538.https://doi.org/10.1016/j.ecosys.2016.02.004

Helpman, E. (2011). The mystery of economic growth. Moscow: Publishing House of E.T. Gaidar Institute.

Hodgson, J. (2003). Economic theory and institutions. Moscow: Business.

Hodgson, J. (2006). Evolutionary and Institutional Economy as New «Mainstream»? Economic Bulletin of Rostov State University, 6(2), 8-21.

Homan, P. (1932). An appraisal of institutional economics. American Economic Review, 22(1), 10-17. Retrieved from https://www.jstor.org/stable/1807255

Iamsiraroj, S. (2016). The foreign direct investment - economic growth nexus. International Review of Economics \& Finance, 42, 116-133. https://doi.org/10.1016/j.iref.2015.10.044

Lucas, R. (1981). Studies in business-cycle theory. MIT Press.

Menard, C. (1996). Economy of organizations. Translation from French. Moscow: Infra-M.

Nelson, R. (2008). Economic development from the perspective of evolutionary economic theory. Oxford Development Studies, 36(1), 9-21. https://doi.org/10.1080/13600810701848037

Nelson, R., \& Winter, S. (2000). Evolutional theory of economic changes. Moscow: Finstatinform.

North, D. (2010). Understanding of the process of economic changes. Moscow: Publishing house GU Higher School of Economics.

Olson, M. (2013). Eminence and decline of the nations. Economic growth, stagflation and social sclerosis. Moscow: New Publishing house.

Ryser, L., Halseth, G., Markey, S., \&Morris, M. (2016). The structural underpinnings impacting rapid growth in resource regions. The Extractive Industries and Society, 3(3), 616-626. https://doi.org/10.1016/j.exis.2016.06.001

Samaniego, R. M., \&Sun, J. Y. (2016).Productivity growth and structural transformation. Review of Economic Dynamics, 21, 266-285. https://doi.org/10.1016/j.red.2015.06.003

Silverberg, G., \& Verspagen, B. (1995). Evolutionary theorizing on economic growth. Discussion paper. MERIT, Maastricht.

Solow, R. (1994). Perspectives of the theory of growth. Journal of Economic Perspectives, 8(1), 45-54. https://doi.org/10.1257/jep.8.1.45

Solow, R. M. (1957).Technical change and the aggregate production function. Review of Economics and Statistics, 39(3),312-320. https://doi.org/10.2307/1926047

Solow, R. M. (1974).The Economics of Resources or the Resources of Economics. The American Economic Review, 64(2), 1-14. https://doi.org/10.1057/9780230523210 13

Solow, R. M.(2007).The last 50 years in growth theory and the next 10. Oxford Review of Economic Policy, $23(1), 3-14$. https://doi.org/10.1093/oxrep/grm004

Veblen, T. (1980). The theory of idle class. Moscow: Progress.

Veblen, T. (2007). The theory of the business enterprise. Moscow: Business.

Vo, L. V., \&Le, H. T. T. (2017).Strategic growth option, uncertainty, and R\&D investment. International Review of Financial Analysis, 51, 16-24. https://doi.org/10.1016/j.irfa.2017.03.002

Williamson, O. (1975). Markets and hierarchies. N.Y.: Prentice-Hall.

Yang, H., \&Jung, W.-S. (2016). Structural efficiency to manipulate public research institution networks. Technological Forecasting and Social Change, 110, 21-32. https://doi.org/10.1016/j.techfore.2015.12.012 